\title{
Usefulness of pulsed arterial spin labeling MR imaging in mesial temporal lobe epilepsy
}

\author{
Young-Min $\operatorname{Lim}^{a, *, 1}$, Yong-Won Cho ${ }^{a, 1}$, Sadat Shamim ${ }^{a}$, Jeffrey Solomon ${ }^{b}$, \\ Rasmus Birn ${ }^{c}$, Wen Ming Luh ${ }^{d}$, William D. Gaillard ${ }^{a}$, \\ Eva K. Ritzl ${ }^{a}$, William H. Theodore ${ }^{a}$
}

a Clinical Epilepsy Section, NINDS, NIH, Bethesda, MD 20892, United States

b Diagnostic Radiology Department, Clinical Center, NIH, Bethesda, MD 20892, United States

c Laboratory of Brain and Cognition, NIMH, NIH, Bethesda, MD 20892, United States

d OFC DIR, NIMH, NIH, Bethesda, MD 20892, United States

Received 21 November 2007; received in revised form 6 June 2008; accepted 11 August 2008

\author{
KEYWORDS \\ Arterial spin labeling; \\ Magnetic resonance \\ imaging; \\ Cerebral blood flow; \\ Temporal lobe \\ epilepsy; \\ $\mathrm{H}_{2}{ }^{15} \mathrm{O}$ PET
}

\begin{abstract}
Summary
Purpose: Arterial spin labeling (ASL) is a developing magnetic resonance imaging (MRI) method for noninvasive measurement of cerebral blood flow (CBF). The purpose of this study was to evaluate the usefulness of ASL for detecting interictal temporal hypoperfusion in temporal lobe epilepsy (TLE). ASL-derived CBF measurements were compared with those derived from $\mathrm{H}_{2}{ }^{15} \mathrm{O}$ positron emission tomography (PET).

Methods: 11 normal controls and 10 patients with medically intractable TLE were studied. Pulsed ASL (PASL) with quantitative imaging of perfusion using a single subtraction, second version (QUIPSS II) was performed in all subjects and $\mathrm{H}_{2}{ }^{15} \mathrm{O}$ PET was performed in patients. Regional $\mathrm{CBF}$ values in the mesial and lateral temporal lobes were measured utilizing quantitative analysis of perfusion images. A perfusion asymmetry index (Al) was calculated for each region.

Results: In patients, mean $\mathrm{CBF}$ in the mesial temporal lobe was not significantly different between PASL and $\mathrm{H}_{2}{ }^{15} \mathrm{O}$ PET, and ipsilateral mesial temporal CBF was lower than contralateral CBF with both techniques. PASL detected significant mesial temporal perfusion asymmetry agreeing with EEG laterality in four patients. $\mathrm{H}_{2}{ }^{15} \mathrm{O}$ PET found ipsilateral interictal hypoperfusion in three. Both scans found unilateral hypoperfusion in one patient with bilateral EEG discharges.

Conclusions: Pulsed ASL may be a promising approach to detecting interictal hypoperfusion in TLE. This method has potential as a clinical alternative to $\mathrm{H}_{2}{ }^{15} \mathrm{O}$ PET due to noninvasiveness and easy accessibility.

(c) 2008 Published by Elsevier B.V.
\end{abstract}

* Corresponding author.at: Clinical Epilepsy Section, NIH Building 10, Room 5N-258, Bethesda, MD 20892, United States.

Tel.: +1 301451 8486; fax: +1 3014022871.

E-mail address: limy@ninds.nih.gov (Y.-M. Lim).

1 These authors are co-first authors. 


\section{Introduction}

Precise localization of the epileptogenic zone is essential for the successful surgical treatment of temporal lobe epilepsy (TLE), the most common type of medically intractable epilepsy in adults (Hardy et al., 2003). In addition to structural magnetic resonance imaging (MRI), functional imaging, including the measurement of regional cerebral blood flow (CBF) and metabolism in temporal epileptogenic zones has been investigated widely (Duncan, 1992; Duncan, 1997). Interictal $\left[{ }^{18} \mathrm{~F}\right]$ fluorodeoxyglucose-positron emission tomography $\left({ }^{18} \mathrm{FDG}-\mathrm{PET}\right)$ is reported to have sensitivity of $60-90 \%$ (Theodore et al., 1983; Engel et al., 1990; Spencer, 1994; Theodore et al., 1997; Van Paesschen et al., 2007). In contrast, interictal CBF studies using single photon emission computed tomography (SPECT) or $\mathrm{H}_{2}{ }^{15} \mathrm{O}$ PET scan have not provided reliable localizing information (Stefan et al., 1987; Rowe et al., 1991; Spencer, 1994; Theodore et al., 1994). A meta-analysis found that sensitivity for interictal SPECT was 44\% (32.3-55.3\%) (Devous et al., 1998). Relatively poor spatial resolution of current perfusion techniques may be one of the reasons why CBF measurement has limited localizing value, although uncoupling of metabolism and perfusion in the epileptogenic zone remains possible (Gaillard et al., 1995; Lee et al., 2001).

Recently several new magnetic resonance imaging methods have been introduced to study local cerebral perfusion in TLE (Detre and Alsop, 1999; Wu et al., 1999; Liu et al., 2001; Wolf et al., 2001; Alsop et al., 2002; O’Brien et al., 2007). Perfusion MRI has substantial advantages over SPECT and $\mathrm{PET}$, including noninvasiveness, no radiation exposure, easier accessibility, and higher spatial resolution, especially at high magnetic field (Calamante et al., 1999; Carroll et al., 2002; Zappe et al., 2007). Arterial spin labeling (ASL), a developing MRI technique, is capable of quantifying local CBF by measuring the inflow of magnetically labeled arterial blood into the target region (Detre et al., 1992; Williams et al., 1992; Wong et al., 1997; Buxton et al., 1998; Wong et al., 1999). However, systemic errors in CBF quantitation such as transit delays and contamination by intravascular signal have hindered clinical application of ASL (Wong et al., 1997; Golay et al., 2004; Wong, 2005). Quantitative imaging of perfusion using a single subtraction, second version (QUIPSS II) is a pulsed ASL (PASL) technique, which has been developed to reduce these limitations (Wong et al., 1997, 1998a,b; Luh et al., 1999; Wong et al., 1999; Barbier et al., 2001).

The purpose of this study was to determine whether PASL MRI using QUIPSS II saturated pulse could be a useful clinical tool to lateralize epileptic foci in TLE. We used highresolution PASL MRI to provide better spatial coverage and higher temporal resolution than previous studies. To assess the feasibility of PASL for the detection of lateralized temporal hypoperfusion, we compared the CBF values obtained from PASL to those derived from $\mathrm{H}_{2}{ }^{15} \mathrm{O}$ PET.

\section{Methods}

\section{Subject selection}

We included 11 healthy volunteers (6 men and 5 women; mean age \pm S.D. $34.8 \pm 13.1$ years; range, $17-56$ years)
Table 1 Clinical characteristics of patients

\begin{tabular}{lllll}
\hline $\begin{array}{l}\text { Patient } \\
\text { number }\end{array}$ & $\begin{array}{l}\text { Age } \\
\text { (years) }\end{array}$ & Sex & EEG focus & MRI findings \\
\hline 1 & 55 & M & Left & Left HS \\
2 & 27 & M & Left & Normal \\
3 & 56 & M & Right & Right HA \\
4 & 24 & M & Left & Normal \\
5 & 27 & F & Left & Normal \\
6 & 46 & F & Left & Left HS \\
7 & 19 & M & Right & Normal \\
8 & 30 & M & Bilateral & Normal \\
9 & 53 & M & Left & Left HS \\
10 & 22 & F & Left & Normal \\
\hline
\end{tabular}

M, male; F, female; HS, hippocampal sclerosis; HA, hippocampal atrophy.

and 10 patients ( 7 men and 3 women; mean age \pm S.D. $35.9 \pm 14.8$; range $19-56$ years), referred to the clinical epilepsy section, National Institute of Neurological Disorders and Stroke, National Institute of Health. All patients received ictal scalp video-electroencephalography (EEG) monitoring to localize epileptozenic foci, and four patients underwent subdural EEG monitoring after all imaging studies. Patients with evidence of structural lesions on MRI (except mesial temporal sclerosis) or progressive neurologic process were excluded. None of the patients had a seizure for at least $72 \mathrm{~h}$ prior to brain perfusion imaging or a secondarily generalized tonic clonic seizure for at least 1 week before the studies. Informed consent was obtained from all subjects. The study was approved by the NINDS institutional review board.

Lateralization based on ictal video-EEG and structural routine MRI is summarized in Table 1 . The epileptic foci were left-sided in seven patients and right-sided in two patients. One had bilateral temporal lobe epilepsy. Four patients showed abnormal MRI findings compatible with mesial temporal sclerosis on the same side of EEG lateralization. Temporal lobe resection was carried out in three patients $(1,5$, and 6$)$ and hippocampal sclerosis was present on histopathological examination.

\section{Magnetic resonance imaging}

Perfusion MRI scans were performed on patients and controls, using a GE Signa 3T MRI scanner. ASL perfusion image was obtained with QUIPSS II sequence, which is based on a proximal inversion with a control for off resonance effects (PICORE) (Wong et al., 1997, 1998b; Luh et al., 1999). A $10-\mathrm{cm}$ tagging slab was generated by a $15-\mathrm{ms}$ hyperbolic secant inversion pulse, leaving a $1-\mathrm{cm}$ gap between the distal end of the tag and the proximal edge of the imaging slice. Each perfusion scan comprised a series of 150 echo-planer images (EPI) in which blood was alternately tagged and untagged. The former was referred to as the tag image and the latter as the control image. For each scan, a volume consisting of five oblique axial slices with $7 \mathrm{~mm}$ thickness was chosen to cover the temporal area. Imaging parameters were as follows: TR/TE $=2500 \mathrm{~ms} / 30 \mathrm{~ms}, \mathrm{TI}_{1}$ 
(the first inversion time in the QUIPSS II) $=700 \mathrm{~ms}, \mathrm{TI}_{2}$ (the second inversion time $)=1400 \mathrm{~ms}$, field of view $(F O V)=24 \mathrm{~cm}$ and matrix size $=64 \mathrm{~A} \times 64 \mathrm{~A}$ short imaging series comprising 10 volumes of EPI, with the same slices and resolution as the perfusion sequence, were additionally acquired. Anatomical MRI was collected using a high-resolution threedimensional (3D) spoiled gradient recalled echo (SPGR) sequence.

\section{$\mathrm{H}_{2}{ }^{15} \mathrm{O}$ PET imaging}

$\mathrm{H}_{2}{ }^{15} \mathrm{O}$ PET studies were performed on all patients using a GE Advance Tomography (GE, Waukesha, WI), which simultaneously makes 35 simultaneous slices with $4.25 \mathrm{~mm}$ inter-slice separation. The spatial resolution in all directions was $6 \mathrm{~mm}$ full width at half maximum (FWHM) after reconstruction. A molded thermoplastic facemask was applied to reduce head motion, and EEG was continuously recorded to ensure the interictal state. Eight-minute transmission scan was acquired for the purpose of attenuation correction. Following the transmission scan, an intravenous bolus of $10 \mathrm{mCi} 15 \mathrm{O}-\mathrm{H}_{2} \mathrm{O}$ was administrated and continuous arterial blood measurements were performed with an automatic blood counter. A single 60 -s scan was acquired in $3 \mathrm{D}$ mode and quantitative $\mathrm{CBF}$ maps were generated using the measured arterial input function (Giovacchini et al., 2005).

\section{Data processing}

ASL data were corrected for head motion using a 3D rigid body registration algorithm. To improve the efficacy of registration, nonbrain tissue was first removed from structural MRI using the brain extraction tool (Smith, 2002). The 150th volume of ASL images was co-registered to the de-skulled high-resolution anatomical MRI with the FMRIB's linear image registration tool (FLIRT) using 6 degrees of freedom (DOF) and the mutual information cost function (Jenkinson and Smith, 2001). The fit was qualitatively assessed by fusion of the co-registered ASL image with structural MRI. This fused image was also used to determine on which MRI sections the regions of interest (ROI) could be drawn such that the ASL and anatomical MRI images spatially overlapped well. The $\mathrm{H}_{2}{ }^{15} \mathrm{O}$ PET flow image was also registered to the structural MRI using a 6 DOF registration with mutual information cost function. The PET data were corrected for partial volume effects (Giovacchini et al., 2005).

ROls were manually defined in mesial and lateral temporal lobes by one investigator (Y.M.L.) to maintain consistency. Medial temporal ROls included amygdala, hippocampus, and parahippocampus; lateral temporal ROls included superior, middle, and inferior temporal lobes. Large regions were ensured to boost signal-to-noise ratio (SNR) and the specification of individual structures was not done. All ROI drawn on anatomical MRI were then applied to both registered $\mathrm{ASL}$ and $\mathrm{H}_{2}{ }^{15} \mathrm{O}$ PET images. Mean $\mathrm{CBF}$ values for each ROI were calculated by the following methods (see the detailed description below).

\section{Quantitation of regional CBF}

In pulsed ASL, a difference signal between tag and control images $(\Delta M)$ is proportional to CBF and given by

$$
\Delta M=2 \cdot M_{\mathrm{OB}} \cdot \mathrm{CBF} \cdot \mathrm{TI}_{1} \cdot q \cdot \exp \left(-\frac{\mathrm{TI}_{2}}{T_{1 \mathrm{~B}}}\right)
$$

$$
\operatorname{CBF}\left(\mathrm{s}^{-1}\right)=\frac{\Delta M}{2 \cdot \mathrm{M}_{\mathrm{OB}} \cdot \mathrm{TI}_{1} \cdot q \cdot \exp \left(-\mathrm{TI}_{2} / T_{1 \mathrm{~B}}\right)}
$$

where $T_{1 \mathrm{~B}}$ is the $T_{1}$ of blood that is assumed to be $1.5 \mathrm{~s}$ at $3 T$. $q$ is a correction factor depending on the exchange time and tissue $T_{1}$, which is assumed to be 1 for gray matter. $M_{\mathrm{OB}}$ is the signal intensity of fully relaxed blood in the signal unit and is estimated as:

$$
M_{\mathrm{OB}}=1.06 \cdot M_{\mathrm{OW}} \cdot \exp \left(\frac{\mathrm{TE}}{T_{2 \mathrm{~W}}^{*}}\right) \exp \left(-\frac{\mathrm{TE}}{T_{2 \mathrm{~B}}^{*}}\right)
$$

The factor 1.06 is the ratio of blood to white matter from a proton density image as measured in a previous study (Wong et al., 1998b). Mow is the signal intensity of white matter in EPI sequence with infinite TR. This value can be obtained from the first image of the short imaging run of EPI. $T_{2 \mathrm{~W}}^{*}$ is the $T_{2}{ }^{*}$ of white matter and $T_{2 \mathrm{~B}}^{*}$ is the $T_{2}{ }^{*}$ of arterial blood. $T_{2 \mathrm{~W}}^{*}$ is assumed to be $40 \mathrm{~ms}$ and $T_{2 \mathrm{~B}}^{*}$ is estimated to be $100 \mathrm{~ms}$. Due to $T_{2}{ }^{*}$ decay, the average signal intensity measured from pure white matter $\left(S_{\mathrm{W}}\right)$ is $M_{\mathrm{OW}} \cdot \exp \left(-\mathrm{TE} / T_{2 \mathrm{~B}}^{*}\right)$. The measured ASL signal difference $(\Delta S)$ has also $T_{2}{ }^{*}$ weighting since it is acquired with EPI, and consequently it can be expressed as: $\Delta S=\Delta M \cdot \exp \left(-T E / T_{2 B}^{*}\right)$. In order to compute local CBF from measured ASL intensities, equation (1b) can be rewritten as:

$$
\begin{aligned}
\operatorname{CBF}\left(\mathrm{s}^{-1}\right)=\frac{\Delta S}{2 \cdot 1.06 \cdot \mathrm{S}_{\mathrm{W}} \cdot \mathrm{TI}_{1} \cdot q \cdot \exp \left(\mathrm{TE} / T_{2 \mathrm{~W}}^{*}\right)} \\
\cdot \exp \left(-\mathrm{TI}_{2} / T_{1 \mathrm{~B}}\right) \cdot \exp \left(-\mathrm{TE} / T_{2 \mathrm{~B}}^{*}\right)
\end{aligned}
$$

Assuming the brain density of $1 \mathrm{~g} / \mathrm{mL}$, the CBF value in $\mathrm{s}^{-1}$ can be converted to 6000 ( $\mathrm{mL}$ of blood) $/(100 \mathrm{~mL}$ of tissue) $/ \mathrm{min}$.

\section{Statistical analysis}

For patients, a perfusion asymmetry index (AI) was calculated from the mean CBF values identified in each region, using the following formula: Al $(\%)=100 \times$ (ipsilateral - contralateral)/[(ipsilateral + contralateral)/2]. A negative Al implies relative hypoperfusion in the affected temporal lobe. For controls, Al was calculated by the left-right asymmetry: Al (\%) $=100 \times$ (left - right)/[(left + right)/2]. For comparison of patients and controls, the mean values of absolute PASL Al were compared using a Mann-Whitney $U$-test. The correlation of Al values between PASL and PET was examined by Spearman correlation coefficients. A Wilcoxon signed rank test was applied to compare mean mesial temporal CBF estimates between two methods and to find side to side difference in each technique. 
Table 2 Mean mesial temporal blood flows measured with PASL MRI and $\mathrm{H}_{2}{ }^{15}$ O PET

\begin{tabular}{llll}
\hline & PASL CBF (mean \pm S.D. $\mathrm{mL} / 100 \mathrm{~g} / \mathrm{min})$ & PET CBF (mean \pm S.D. $\mathrm{mL} / 100 \mathrm{~g} / \mathrm{min})$ & $p$ value \\
\hline Ipsilateral MTL & $37.69 \pm 17.12$ & $50.06 \pm 17.09$ & 0.11 \\
Contralateral MTL & $45.12 \pm 20.92$ & $54.72 \pm 17.42$ & 0.24 \\
\hline
\end{tabular}

CBF, cerebral blood flow; PASL, pulsed arterial spin labeling; MTL, mesial temporal lobe.

\section{Results}

Table 2 shows mean mesial temporal blood flow obtained from PASL MRI and $\mathrm{H}_{2}{ }^{15} \mathrm{O}$ PET in patients. The mean mesial temporal blood flow on PASL was comparable to PET flow measurement, although there was a nonsignificant trend for PET estimates to be higher $(p>0.1)$. Mesial temporal CBF was significantly decreased ipsilateral to the seizure focus on PASL MRI $(p<0.01)$ as well as $\mathrm{H}_{2}{ }^{15} \mathrm{O}$ PET $(p=0.02)$. In controls, PASL-derived mean $\mathrm{CBF} \pm$ S.D. was $37.99 \pm 6.38 \mathrm{~mL} / 100 \mathrm{~g} / \mathrm{min}$ on the left side and $39.31 \pm 5.09 \mathrm{~mL} / 100 \mathrm{~g} / \mathrm{min}$ on the right side $(p=0.29)$.

The mean absolute $\mathrm{Al} \pm$ S.D. for the mesial temporal region (Fig. 1) was $11.02 \pm 7.81$ (range, 0.48-23.32) in controls and $18.16 \pm 13.37$ (range, 1.83-37.67) in patients $(p=0.26)$; for the lateral temporal region, it was $10.29 \pm 6.78$ (range, 0.19-20.42) in controls and $10.64 \pm 7.38$ (range, $0.33-22.95)$ in patients $(p=0.94)$.

Table 3 shows individual Al data derived from both techniques. Mesial temporal perfusion asymmetries in PASL were greater than $\mathrm{H}_{2}{ }^{15} \mathrm{O}$ PET in six patients. PASL found mesial temporal perfusion asymmetries exceeding 1-S.D. of control mean value in five patients (patients 2, 5, 6, 8, and 9). Significant asymmetries were still observed in three, using the threshold of 2-S.D. beyond control mean. Based on our laboratory $\mathrm{H}_{2}{ }^{15} \mathrm{O}$ PET data, the mean absolute perfusion $\mathrm{Al}$ for hippocampal region is $8.58 \pm 6.34$ (range, $0.17-16.59$ ) in normal controls. This value was used as control mean \pm S.D. for $\mathrm{H}_{2}{ }^{15} \mathrm{O}$ PET data. $\mathrm{H}_{2}{ }^{15} \mathrm{O}$ PET found significant hypoperfusion in the affected temporal lobe in three (patients 1 ,

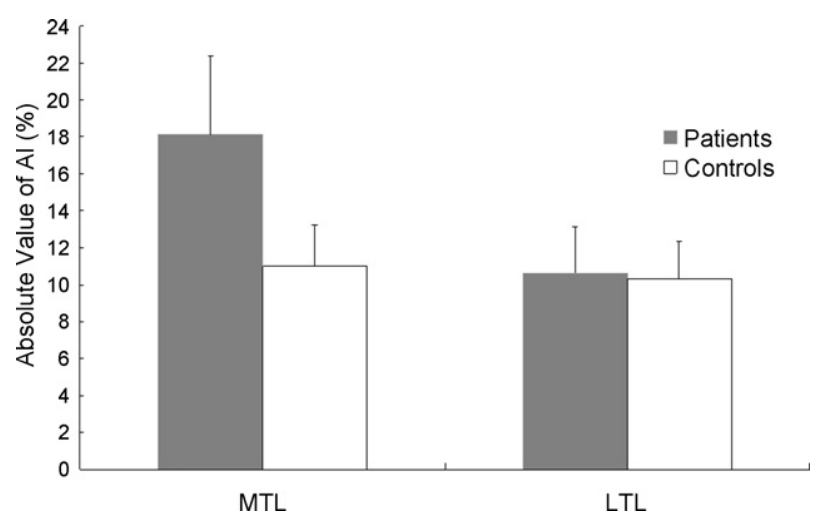

Figure 1 Bar graph comparing mean absolute asymmetric indices of temporal perfusion between patients and controls. Patients had greater perfusion asymmetry in the mesial temporal lobe than controls, but the difference between groups did not reach statistical significance $(p=0.26)$. Data are expressed as mean \pm standard error of the mean. Al, asymmetric index; MTL, mesial temporal lobe; LTL, lateral temporal lobe.
Table 3 Asymmetric indices of temporal lobe perfusion in TLE patients

\begin{tabular}{|c|c|c|c|c|}
\hline \multirow[t]{2}{*}{ Patient number } & \multicolumn{2}{|c|}{ PASL MRI AI (\%) } & \multicolumn{2}{|c|}{$\mathrm{H}_{2}{ }^{15} \mathrm{O}$ PET Al (\%) } \\
\hline & MTL & LTL & MTL & LTL \\
\hline 1 & -9.55 & -7.70 & -22.80 & -16.31 \\
\hline 2 & -26.48 & -0.33 & -5.20 & -7.97 \\
\hline 3 & -1.94 & -15.91 & -3.30 & 1.27 \\
\hline 4 & -1.83 & -2.57 & -15.84 & 3.61 \\
\hline 5 & -37.67 & -11.49 & 5.23 & 0.47 \\
\hline 6 & -28.03 & -18.88 & -8.98 & -6.29 \\
\hline 7 & -5.77 & -3.19 & -8.32 & 10.83 \\
\hline 8 & -35.40 & -10.28 & -12.05 & -37.30 \\
\hline 9 & -19.10 & -22.95 & -17.04 & -24.92 \\
\hline 10 & -15.80 & -13.10 & -5.42 & -14.44 \\
\hline
\end{tabular}

PASL, pulsed arterial spin labeling; Al, asymmetric index; MTL, mesial temporal lobe; LTL, lateral temporal lobe.

4 and 9) at the 1-S.D. threshold of control mean and in one (patient 1) at the 2-S.D. threshold. The direction of the asymmetry with PASL was in agreement with ictal videoEEG lateralization in each case except for patient 8 . While EEG showed bilateral seizure foci in patient 8 , PASL found interictal hypoperfusion in the left mesial temporal lobe and ${ }^{18}$ FDG-PET scan revealed glucose hypometabolism in the left lateral temporal region. Fig. 2 is an example of the CBF images acquired from the same slices of PASL and $\mathrm{H}_{2}{ }^{15} \mathrm{O}$ PET in patient 6. Compared with $\mathrm{H}_{2}{ }^{15} \mathrm{O}$ PET image, the PASL CBF map showed a more prominent perfusion decrease in the mesial temporal lobe ipsilateral to the EEG focus. In patient 5, PASL indicated left mesial temporal hypoperfusion, which coincided with EEG laterality, whereas $\mathrm{H}_{2}{ }^{15} \mathrm{O}$ PET indicated mild contralateral temporal hypoperfusion that was statistically insignificant. There was no significant correlation between PASL-based $\mathrm{Al}$ and PET-derived Al for the mesial temporal lobe $(r=-0.10, p=0.77)$.

\section{Discussion}

The results of this study suggest that PASL with QUIPSS II is worthy of further study as a potential method for lateralization of epileptic foci by detecting interictal asymmetries in mesial temporal perfusion, particularly in patients with normal MRI. Mesial temporal perfusion asymmetries in PASL were relatively greater than in $\mathrm{H}_{2}{ }^{15} \mathrm{O}$ PET in our study, suggesting PASL MRI might be more sensitive than $\mathrm{H}_{2}{ }^{15} \mathrm{O}$ PET to detect interictal perfusion asymmetries. PASL showed correct lateralization in patient 5 , whereas $\mathrm{H}_{2}{ }^{15} \mathrm{O}$ PET did not. Only one patient did not show agreement in PASL with ictal video-EEG lateralization (case 8 ). The patient had bitemporal seizure foci, but both CBF procedures showed left 


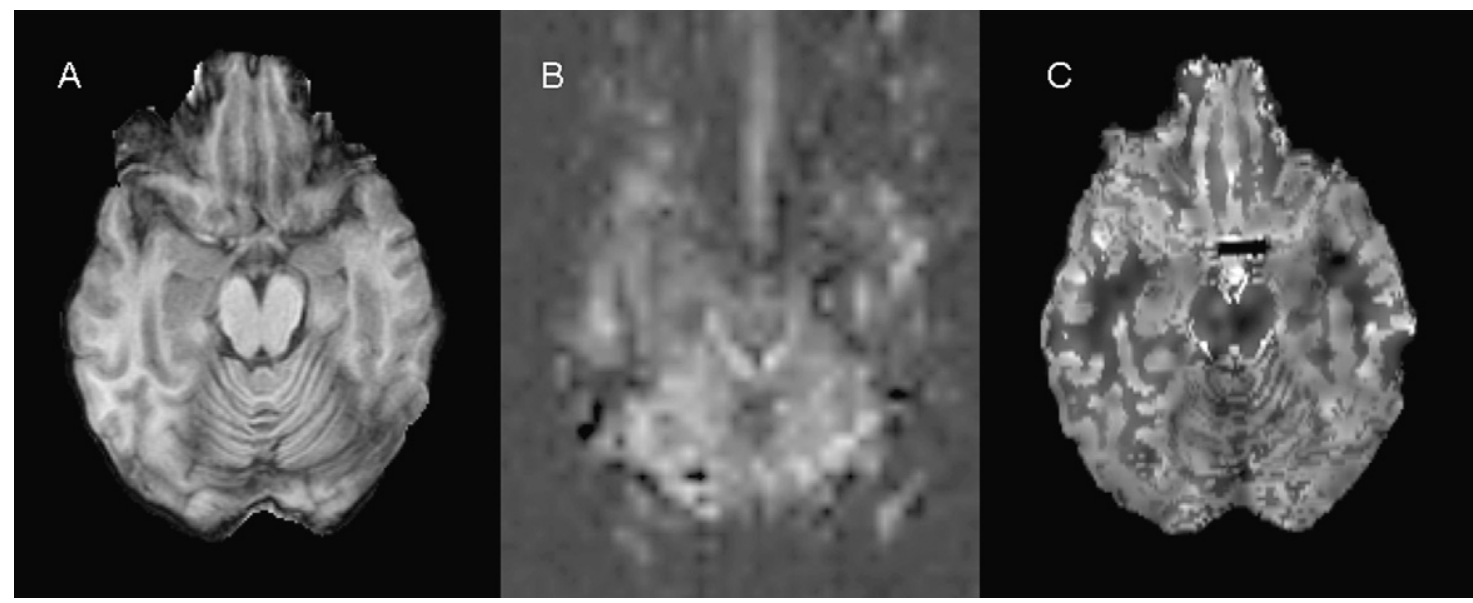

Figure 2 Anatomical MR and perfusion images obtained from a patient with left temporal lobe epilepsy (patient 6). Panel A: axial spoiled gradient recalled echo (SPGR) image; Panel B: pulsed arterial spin labeling (PASL) image at the same anatomic level; Panel $\mathrm{C}: \mathrm{H}_{2}{ }^{15} \mathrm{O}$ PET CBF image at the same anatomic level. PASL CBF map (B) shows more prominent perfusion decrease in the ipsilateral mesial temporal lobe as compared to $\mathrm{H}_{2}{ }^{15} \mathrm{O}$ PET CBF image (C).

temporal hypoperfusion, suggesting the possibility of lateralization.

Previous ASL studies reported similar findings in patients with TLE. In a study of continuous ASL (CASL) MRI, mesial temporal perfusion was more asymmetric in patients than in controls, and the perfusion Al correlated with asymmetries derived from FDG PET metabolism and hippocampal volume (Wolf et al., 2001). PASL may be superior to CASL. CASL theoretically has higher signal-to-noise ratio than PASL, but in practice, the ratio advantage is only $0-25 \%$ because of flow-velocity dependent imperfect tagging efficiency and vascular artifact (Wong et al., 1999). CASL is more sensitive to magnetization transfer (MT) effects than PASL due to a long-off resonance radiofrequency (RF) pulse. MT related attenuation of the tissue signal is negligible in PASL (Wong et al., 1998b; Calamante et al., 1999; Buxton, 2005). Moreover, PASL may be more practical at high magnetic fields $(\geq 3.0 \mathrm{~T})$ because CASL needs more RF power at high fields for the same RF amplitude (Wong et al., 1999) and can be restricted by system performance capability and FDA guidelines about RF energy absorption per unit mass (Liu and Brown, 2007).

In another study using flow-sensitive alternating inversion recovery with half-Fourier single shot turbo spin-echo (FAIR-HASTE), the temporal perfusion AI on PASL correlated with those on $\mathrm{H}_{2}{ }^{15} \mathrm{O}$ PET (Liu et al., 2001). However, lateralization based on PASL was not compared with seizure laterality based on EEG. Unlike the FAIR-HASTE study, there was no correlation of Al values between PASL and PET in our study. The reasons are not clear why there is discrepancy between two measurements. Several factors could account for the discrepancy, including different spatial resolution and partial volume effects (Ye et al., 2000). In prototype PASL techniques including echoplanar imaging and signal targeting with alternating RF (EPISTAR) and FAIR, there are spatially variable transit delays of blood from the tagging region to the imaging slice. QUIPSS II is a modification of conventional PASL techniques that attempts to minimize transit time effects by application of additional saturation pulse to directly control the time duration of the tag (Wong et al., 1997, 1998a,b; Luh et al., 1999; Golay et al., 2004).
This method does not require an additional coil for tagging and allows multislice acquisition. However, incomplete saturation of arterial spins and spatial mismatch between the distal saturation edge and inversion slice profiles can make CBF measurement inaccurate (Luh et al., 1999).

As compared to PET scan, ASL provides better spatial and temporal resolution, assuming adequate SNR, and performs multiple repeated measurements as clinically indicated (Carroll et al., 2002; Wintermark et al., 2005; Donahue et al., 2006; Zappe et al., 2007). It is entirely noninvasive, easily accessible, and requires no injection or ionizing radiation, allowing CBF imaging for children (Wintermark et al., 2005; Petersen et al., 2006; Zappe et al., 2007). ASL has been reported to have favorable reproducibility, although this could be restricted by low SNR (Parkes et al., 2004; Jahng et al., 2005).

Perfusion decrease in the affected mesial temporal lobe could result from mesial temporal atrophy. However, clear perfusion asymmetry on PASL was identified despite normal structural MRI in cases 2, 5 and 8. Moreover, high field PASL imaging used in this study was acquired at high spatial resolution, reducing alterations of true CBF values due to partial volume effect (Donahue et al., 2006). It is possible that functional alterations such as receptor loss, hypoperfusion, or hypometabolism may precede structural atrophy in the epileptic zone (Giovacchini et al., 2005).

In summary, the results of this study suggested that PASL may have potential as a clinical alternative to $\mathrm{H}_{2}{ }^{15} \mathrm{O}$ PET for quantitative assessment of CBF in patients with epilepsy.

\section{References}

Alsop, D.C., Connelly, A., Duncan, J.S., Hufnagel, A., Pierpaoli, C., Rugg-Gunn, F.J., 2002. Diffusion and perfusion MRI in epilepsy. Epilepsia 43, 69-77.

Barbier, E.L., Lamalle, L., Decorps, M., 2001. Methodology of brain perfusion imaging. J. Magn. Reson. Imaging 13, 496-520.

Buxton, R.B., Frank, L.R., Wong, E.C., Siewert, B., Warach, S., Edelman, R.R., 1998. A general kinetic model for quantitative 
perfusion imaging with arterial spin labeling. Magn. Reson. Med. 40, 383-396.

Buxton, R.B., 2005. Quantifying CBF with arterial spin labeling. J. Magn. Reson. Imaging 22, 723-726.

Calamante, F., Thomas, D.L., Pell, G.S., Wiersma, J., Turner, R., 1999. Measuring cerebral blood flow using magnetic resonance imaging techniques. J. Cereb. Blood Flow Metab. 19, 701-735.

Carroll, T.J., Teneggi, V., Jobin, M., Squassante, L., Treyer, V., Hany, T.F., Burger, C., Wang, L., Bye, A., Von Schulthess, G.K., Buck, A., 2002. Absolute quantification of cerebral blood flow with magnetic resonance, reproducibility of the method, and comparison with $\mathrm{H}_{2}{ }^{15} \mathrm{O}$ positron emission tomography. J. Cereb. Blood Flow Metab. 22, 1149-1156.

Detre, J.A., Leigh, J.S., Williams, D.S., Koretsky, A.P., 1992. Perfusion imaging. Magn. Reson. Med. 23, 37-45.

Detre, J.A., Alsop, D.C., 1999. Perfusion magnetic resonance imaging with continuous arterial spin labeling: methods and clinical applications in the central nervous system. Eur. J. Radiol. 30, 115-124.

Devous Sr., M.D., Thisted, R.A., Morgan, G.F., Leroy, R.F., Rowe, C.C., 1998. SPECT brain imaging in epilepsy: a meta-analysis. J. Nucl. Med. 39, 285-293.

Donahue, M.J., Lu, H., Jones, C.K., Pekar, J.J., van Zijl, P.C., 2006. An account of the discrepancy between MRI and PET cerebral blood flow measures. A high-field MRI investigation. NMR Biomed. 19, 1043-1054.

Duncan, J.S., 1997. Imaging and epilepsy. Brain 120, 339-377.

Duncan, R., 1992. Epilepsy, cerebral blood flow, and cerebral metabolic rate. Cerebrovasc. Brain Metab. Rev. 4, 105121.

Engel Jr., J., Henry, T.R., Risinger, M.W., Mazziotta, J.C., Sutherling, W.W., Levesque, M.F., Phelps, M.E., 1990. Presurgical evaluation for partial epilepsy: relative contributions of chronic depthelectrode recordings versus FDG-PET and scalp-sphenoidal ictal EEG. Neurology 40, 1670-1677.

Gaillard, W.D., Fazilat, S., White, S., Malow, B., Sato, S., Reeves, P., Herscovitch, P., Theodore, W.H., 1995. Interictal metabolism and blood flow are uncoupled in temporal lobe cortex of patients with complex partial epilepsy. Neurology 45, 18411847.

Giovacchini, G., Toczek, M.T., Bonwetsch, R., Bagic, A., Lang, L., Fraser, C., Reeves-Tyer, P., Herscovitch, P., Eckelman, W.C., Carson, R.E., Theodore, W.H., 2005. 5- $\mathrm{HT}_{1 \mathrm{~A}}$ receptors are reduced in temporal lobe epilepsy after partial-volume correction. J. Nucl. Med. 46, 1128-1135.

Golay, X., Hendrikse, J., Lim, T.C., 2004. Perfusion imaging using arterial spin labeling. Top Magn. Reson. Imaging 15, 10-27.

Hardy, S.G., Miller, J.W., Holmes, M.D., Born, D.E., Ojemann, G.A., Dodrill, C.B., Hallam, D.K., 2003. Factors predicting outcome of surgery for intractable epilepsy with pathologically verified mesial temporal sclerosis. Epilepsia 44, 565-568.

Jahng, G.H., Song, E., Zhu, X.P., Matson, G.B., Weiner, M.W., Schuff, N., 2005. Human brain: reliability and reproducibility of pulsed arterial spin-labeling perfusion MR imaging. Radiology 234, 909-916.

Jenkinson, M., Smith, S., 2001. A global optimisation method for robust affine registration of brain images. Med. Image Anal. 5, $143-156$.

Lee, D.S., Lee, J.S., Kang, K.W., Jang, M.J., Lee, S.K., Chung, J.K., Lee, M.C., 2001. Disparity of perfusion and glucose metabolism of epileptogenic zones in temporal lobe epilepsy demonstrated by SPM/SPAM analysis on ${ }^{15} \mathrm{O}$ water PET, $\left[{ }^{18} \mathrm{~F}\right] \mathrm{FDG}-\mathrm{PET}$, and [ ${ }^{99 \mathrm{~m} T \mathrm{TC}]-H M P A O}$ SPECT. Epilepsia 42, 1515-1522.

Liu, H.L., Kochunov, P., Hou, J., Pu, Y., Mahankali, S., Feng, C.M., Yee, S.H., Wan, Y.L., Fox, P.T., Gao, J.H., 2001. Perfusionweighted imaging of interictal hypoperfusion in temporal lobe epilepsy using FAIR-HASTE: comparison with $\mathrm{H}_{2}{ }^{15} \mathrm{O}$ PET measurements. Magn. Reson. Med. 45, 431-435.
Liu, T.T., Brown, G.G., 2007. Measurement of cerebral perfusion with arterial spin labeling Part 1. Methods. J. Int. Neuropsychol. Soc. 13, 1-9.

Luh, W.M., Wong, E.C., Bandettini, P.A., Hyde, J.S., 1999. QUIPSS II with thin-slice $\mathrm{TI}_{1}$ periodic saturation: a method for improving accuracy of quantitative perfusion imaging using pulsed arterial spin labeling. Magn. Reson. Med. 41, 1246-1254.

O’Brien, T.J., David, E.P., Kilpatrick, C.J., Desmond, P., Tress, B., 2007. Contrast-enhanced perfusion and diffusion MRI accurately lateralize temporal lobe epilepsy: a pilot study. J. Clin. Neurosci. 14, 841-849.

Parkes, L.M., Rashid, W., Chard, D.T., Tofts, P.S., 2004. Normal cerebral perfusion measurements using arterial spin labeling: reproducibility, stability, and age and gender effects. Magn. Reson. Med. 51, 736-743.

Petersen, E.T., Zimine, I., Ho, Y.C., Golay, X., 2006. Non-invasive measurement of perfusion: a critical review of arterial spin labelling techniques. Br. J. Radiol. 79, 688-701.

Rowe, C.C., Berkovic, S.F., Austin, M.C., Saling, M., Kalnins, R.M., McKay, W.J., Bladin, P.F., 1991. Visual and quantitative analysis of interictal SPECT with technetium-99m-HMPAO in temporal lobe epilepsy. J. Nucl. Med. 32, 1688-1694.

Smith, S.M., 2002. Fast robust automated brain extraction. Hum. Brain Mapp. 17, 143-155.

Spencer, S.S., 1994. The relative contributions of MRI, SPECT, and PET imaging in epilepsy. Epilepsia 35 (Suppl. 6), S72-89.

Stefan, H., Pawlik, G., Bocher-Schwarz, H.G., Biersack, H.J., Burr, W., Penin, H., Heiss, W.D., 1987. Functional and morphological abnormalities in temporal lobe epilepsy: a comparison of interictal and ictal EEG, CT, MRI SPECT and PET. J. Neurol. 234, 377-384.

Theodore, W.H., Newmark, M.E., Sato, S., Brooks, R., Patronas, N., De La Paz, R., DiChiro, G., Kessler, R.M., Margolin, R., Manning, R.G., et al., 1983. [ $\left.{ }^{18} \mathrm{~F}\right]$ fluorodeoxyglucose positron emission tomography in refractory complex partial seizures. Ann. Neurol. 14, 429-437.

Theodore, W.H., Gaillard, W.D., Sato, S., Kufta, C., Leiderman, D., 1994. Positron emission tomographic measurement of cerebral blood flow and temporal lobectomy. Ann. Neurol. 36, 241-244.

Theodore, W.H., Sato, S., Kufta, C.V., Gaillard, W.D., Kelley, K., 1997. FDG-positron emission tomography and invasive EEG: seizure focus detection and surgical outcome. Epilepsia 38, 81-86.

Van Paesschen, W., Dupont, P., Sunaert, S., Goffin, K., Van Laere, K., 2007. The use of SPECT and PET in routine clinical practice in epilepsy. Curr. Opin. Neurol. 20, 194-202.

Williams, D.S., Detre, J.A., Leigh, J.S., Koretsky, A.P., 1992. Magnetic resonance imaging of perfusion using spin inversion of arterial water. Proc. Natl. Acad. Sci. U.S.A. 89, 212216.

Wintermark, M., Sesay, M., Barbier, E., Borbely, K., Dillon, W.P., Eastwood, J.D., Glenn, T.C., Grandin, C.B., Pedraza, S., Soustiel, J.F., Nariai, T., Zaharchuk, G., Caille, J.M., Dousset, V., Yonas, H., 2005. Comparative overview of brain perfusion imaging techniques. Stroke 36, e83-99.

Wolf, R.L., Alsop, D.C., Levy-Reis, I., Meyer, P.T., Maldjian, J.A., Gonzalez-Atavales, J., French, J.A., Alavi, A., Detre, J.A., 2001. Detection of mesial temporal lobe hypoperfusion in patients with temporal lobe epilepsy by use of arterial spin labeled perfusion MR imaging. AJNR Am. J. Neuroradiol. 22, 1334-1341.

Wong, E.C., Buxton, R.B., Frank, L.R., 1997. Implementation of quantitative perfusion imaging techniques for functional brain mapping using pulsed arterial spin labeling. NMR Biomed. 10, 237-249.

Wong, E.C., Buxton, R.B., Frank, L.R., 1998a. A theoretical and experimental comparison of continuous and pulsed arterial spin labeling techniques for quantitative perfusion imaging. Magn. Reson. Med. 40, 348-355. 
Wong, E.C., Buxton, R.B., Frank, L.R., 1998b. Quantitative imaging of perfusion using a single subtraction (QUIPSS and QUIPSS II). Magn. Reson. Med. 39, 702-708.

Wong, E.C., Buxton, R.B., Frank, L.R., 1999. Quantitative perfusion imaging using arterial spin labeling. Neuroimaging Clin. N. Am. 9, 333-342.

Wong, E.C., 2005. Quantifying CBF with pulsed ASL: technical and pulse sequence factors. J. Magn. Reson. Imaging. 22, 727731.

Wu, R.H., Bruening, R., Noachtar, S., Arnold, S., Berchtenbreiter, C., Bartenstein, P., Drzezga, A., Tatsch, K., Reiser, M., 1999.
MR measurement of regional relative cerebral blood volume in epilepsy. J. Magn. Reson. Imaging 9, 435-440.

Ye, F.Q., Berman, K.F., Ellmore, T., Esposito, G., van Horn, J.D., Yang, Y., Duyn, J., Smith, A.M., Frank, J.A., Weinberger, D.R., McLaughlin, A.C., 2000. $\mathrm{H}_{2}{ }^{15} \mathrm{O}$ PET validation of steady-state arterial spin tagging cerebral blood flow measurements in humans. Magn. Reson. Med. 44, 450-456.

Zappe, A.C., Reichold, J., Burger, C., Weber, B., Buck, A., Pfeuffer, J., Logothetis, N.K., 2007. Quantification of cerebral blood flow in nonhuman primates using arterial spin labeling and a twocompartment model. Magn. Reson. Imaging 25, 775-783. 